\title{
LA INTRODUCCIÓN DE LAS ARMAS DE FUEGO EN JAPÓN
}

\author{
Ainhoa Reyes Manzano \\ Universidad de La Rioja
}

RESUMEN: La llegada a Japón de las armas de fuego supuso una revolución militar que propició la ruptura del equilibrio bélico de la era Sengoku. Durante los siglos XVI y XVII, los japoneses sacaron partido del armamento que compraron a portugueses y jesuitas, del que requisaron en los naufragios a españoles y holandeses, y del que ellos mismos desarrollaron, destacando la fábrica de arcabuces de Sakai.

Palabras clave: Armas, Japón, Filipinas, guerra, jesuitas.

ABSTRACT: The arrival of firearms to Japan meant a revolution in the battlefield. It caused the rupture of the balance of power among daimios during the Sengoku-jidai. During $X V I^{\text {th }}$ and $X V \mathrm{II}^{\text {th }}$ centuries, Japanese people made good use of the European arms that were bought to Portuguese and Jesuits, the ones that were confiscated to Spaniards and Dutch sunk ships, and the ones that were developed by their owns, especially in the arquebus factory of Sakai.

Keywords: Firearms, Japan, Philippines, war, Jesuits.

El Japón del siglo XVI estaba sacudido por un conflicto constante, una guerra civil que se alargaría durante décadas, y en la que numerosos señores feudales pugnaban por hacerse con el control absoluto del país. Sin embargo, la balanza de poder estaba muy equilibrada, ningún ejército sobresalía por encima de otro, y el desarrollo de la guerra parecía no tener fin. En este contexto, cualquier tipo de innovación bélica podía resultar decisiva. No parece imposible suponer a priori que la introducción de las armas de fuego en Japón pudo haber provocado una revolución militar y haber favorecido a aquellos daimios que contrataban con los occidentales, con portugueses al principio, y con españoles, ingleses y holandeses unos años después. 
Las fuentes occidentales sobre el comercio, fabricación y empleo de armas de fuego en Japón son más bien escuetas, aportan alguna información puntual, y obviamente escapa a ellas una actividad que debe ser tomada en consideración: el contrabando y la piratería. Por ello, se ha combinado el estudio de las mismas con la lectura de trabajos modernos especializados y basados en fuentes japonesas, que completan la visión de conjunto. A lo largo de las siguientes páginas se desarrollará un estudio que analiza de manera global, no exhaustiva, el empleo de las armas de fuego en Japón durante los siglos XVI y XVII, prestando especial atención al comercio, al papel que jugaron los misioneros en dichas transacciones y las consecuencias de la implantación de un nuevo modelo bélico.

\section{El tanegashima}

Aunque suele considerarse que las armas de fuego llegaron por primera vez a Japón de la mano de los portugueses, la primera compra constatada fue una pistola que adquirió en 1510 el daimio de Odawara gracias a un mercader chino ${ }^{1}$. El uso de este tipo de armas en Japón no era corriente, pero no es de extrañar que quienes conocieron las propiedades de la pólvora desde más antiguo, las aprovecharan y desarrollaran su aplicación en el campo de batalla.

Han Ilegado hasta nosotros algunas informaciones sobre la arcabucería china, descrita por misioneros, comerciantes o los propios damnificados. El uso de las armas de fuego en este país ya había sido advertido por el navegante Bernardino de Escalante en 1575, a quien el capitán Artieda había informado de la imposibilidad de que España pudiera conquistar China por la fuerza, ya que "tienen todo género de armas que nosotros, y la artillería, juzgándola por algunos vasos que de allí yo he visto, es muy galana y mejor fundida que la nuestra" ${ }^{\prime 2}$. Un año después, el capitán Días de Ceballos informaba sobre la calidad de hombres de que se servía el pirata chino Limahón, que llevaba ya unos años hostigando la costa filipina:

"[los chinos] tienen artillería y pólvora, usan de muy buenos arcabuzes y pieças, de suerte que el infante que trae pica ha de tener çeñido un gran alfanje más largo que çinco palmos, y a las espaldas una gran rodila muy ligera, forman su esquadrón y guarneçiendo de arcabuzeros tan presto con tanto silencio y tan gentil orden como se podría hazer en medio de Italia. No les havemos visto cotas, ny coseletes, ny celadas, pero trahen todo esto hecho de algodón tan firme que un arcabuz de los suyos no lo passa" ${ }^{3}$.

1. TURNBULL, Stephen, Samuráis, La Historia de los Grandes Guerreros de Japón, 2006, London, p. 188.

2. ESCALANTE, Bernardino de, Discurso de la navegación que los portugueses hacen a los reinos y provincias del oriente, Sevilla, 1577, fo 96 ro․

3. Archivo General de Indias, Filipinas, Legajo 34, Número 18. Carta de Díaz de Ceballos al virrey sobre Limajón. Ff. 134r-136v, 1576-06-04 (Manila). 
Sin embargo, también hubo otros españoles más temerarios que sencillamente despreciaban las artes bélicas chinas con atrevidas palabras de orgullo patrio. El riojano Domingo de Salazar, primer arzobispo de Manila, comentaba en 1583 a propósito de la confianza de los gobernadores chinos en su potencial bélico, que no temían "quando les dizen que los españoles los an de sugetar, porque dizen que aunque no tubiesen armas con que se defender, de solos los cuerpos muertos harían muralla para que nadye les entrase. Pero estos bárbaros no an probado para lo que son los españoles ni saben que pocos arcabuçeros de ellos bastan a desbaratar millones de chinos" ${ }^{\prime 4}$.

A pesar de que los japoneses podían haber sacado provecho de las fábricas chinas, el caso citado del daimio de Odawara fue sólo una excepción. Cuando los primeros portugueses Ilegaron a la isla japonesa de Tanegashima, en 1543, el tráfico entre Japón y el continente chino se hallaba congelado desde hacía décadas. De modo que cuando apareció el primer arcabuz de tipo europeo en Japón, el señor feudal local se percató de inmediato del potencial de aquel teppô, "cañón de acero". El encuentro fue de tal importancia que en adelante aquellos arcabuces serían conocidos precisamente con el nombre de tanegashima.

Los japoneses pronto dejaron de depender de las importaciones de mosquetes, ya que no tuvieron mayores problemas en copiar la técnica de los europeos y fabricarlos a gran escala. Las fábricas de mosquetes y arcabuces se multiplicaron por todo el país de una manera progresiva, especialmente en los reinos centrales de Japón, donde sus armeros alcanzaron una gran fama. Fueron precisamente aquellos reinos los primeros en caer bajo el control de Oda Nobunaga quien, una vez los hubo sojuzgado, pudo aprovisionar a sus tropas con armas de fuego y emplearlas de forma masiva por vez primera en la historia militar japonesa (1568-1582) . Pero hubo que esperar hasta los tiempos de Toyotomi Hideyoshi (1586-1598), para que en el ejército de los daimios se integrara la infantería armada con arcabuces.

La infantería comenzó a aumentar en número e importancia durante la guerra Onin (1466-1477), tendencia que no hizo sino desarrollarse durante la era Sengoku (1467-1615), y que se asentó con la introducción de las armas de fuego, especialmente los arcabuces. Se trataba de batallas locales, en las cuales la infantería no tenía los problemas de abastecimiento y movilidad que tendría si tuviera que desplazarse a lo largo de grandes distancias, tal como ocurría en las guerras coetáneas en el continente chino ${ }^{6}$. La infantería japonesa era conocida como ashigaru, literalmente "pies ligeros". El término designaba a aquellos

4. A.G.I., Fil., Leg. 74, N. 22. Carta de Domingo de Salazar sobre China y Japón. 1583-0618 (Manila).

5. STORRY, Richard, A History of Modern Japan, London, 1960, p. 45.

6. VV.AA., Técnicas bélicas del mundo oriental (1200-1860). Equipamiento, técnicas y tácticas de combate, Libsa, 2009, p. 18. 
soldados que no montaban a caballo ni tenían el rango de samuráis ${ }^{7}$. En parte, una de las razones que explica el éxito en la difusión del arcabuz es que, a diferencia del arco o la espada, el arcabuz no necesitaba de un adiestramiento profundo ni de una destreza especial.

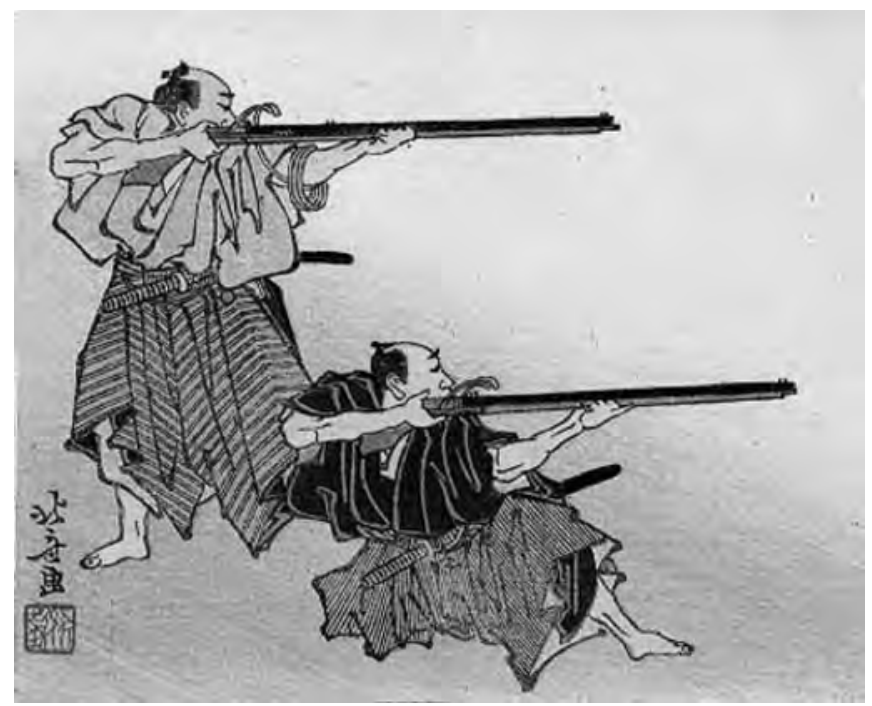

Hombres con arcabuces.

Fuente: http://s 1.zetaboards.com/anthroscape/topic/2033046/1/ Consultado el 25/05/2011.

Si acaso había algún problema con el arma, o el desarrollo de la batalla exigía el paso al combate cuerpo a cuerpo, los soldados no eran equipados sólo con los teppô, sino que también solían ir armados con espadas o lanzas. A modo de protección, era frecuente el uso de armaduras plegables. Sin embargo, el personal auxiliar de los arcabuceros, aquellos encargados de Ilevar la pólvora y preparar los cartuchos, raramente iban equipados con alguna suerte de armadura ligera.

La cadencia de fuego de aquellos arcabuces no sobrepasaba el disparo cada 15-20 segundos, con un arma en manos de un arcabucero bien entrenado. Eso si no se atascaba el cañón, como sucedía a menudo, y teniendo en cuenta que el arcabucero no podía mantener tal ritmo durante largo tiempo. Con Iluvia, si la pólvora o la mecha se humedecían, el arma quedaba inservible, y había que recurrir a armas tradicionales. El radio de alcance de una bala de arcabuz no

7. VV.AA., Técnicas bélicas..., p. 17. 
superaba los 500 metros, pero a más de 200 la fuerza de penetración era más bien escasa y a más de 30 metros perdía ya toda precisión ${ }^{8}$.

Presentaban una gran variedad en cuanto a diseño, calibre, tamaño o peso, pero todos ellos estaban hechos a mano. Como característica especial, los teppo no tenían ningún apoyo para el hombro en la culata. Los japoneses mantuvieron el diseño de los mosquetes que habían copiado de los europeos, prácticamente durante tres siglos, mantuvieron la mecha, pero no introdujeron el pedernal. Se cree que para el siglo XVIII existían unas 250 escuelas de arcabuceros, llegando a considerarse un arte marcial más, el houjyutu. A lo largo de los siglos, el desarrollo de las armas de fuego quedó estancado, y hasta la apertura Meiji (1868) siguió empleándose el arcabuz con sistema de mecha.

La introducción de las armas de fuego supuso una revolución militar tanto para los samuráis como para los ashigaru. Si bien el uso de armas de fuego era patrimonio casi exclusivo de la infantería, los samurais a caballo también tuvieron que cambiar sus tácticas. Se experimentó con el potencial bélico de las armas de fuego por primera vez en un campo de batalla en Uedahara, el año 1548, aunque sólo se trataron de unas primitivas pistolas chinas. Sin embargo, durante los preparativos de la batalla de Kaigawa (1555), los Takeda adquirieron una suma importante de arcabuces de estilo portugués, enviando 300 de éstos para la defensa del castillo de Asahiyama9. Durante esta guerra, librada entre los grandes daimios Takeda Shingen y Uesugui Kenshin, se fueron probando varias combinaciones en el empleo de los arcabuces: al principio, los ashigaru los empleaban de una manera desordenada, pasando de manera aleatoria del arcabuz al arco, y de ahí a la espada o la lanza.

El potencial de los arcabuces no fue plenamente aprovechado hasta unos años más tarde. Un buen ejemplo de que su uso no tuvo continuidad es que el mismo clan Takeda fue derrotado de manera definitiva por Oda Nobunaga en la batalla de Nagasahino (1575) gracias al buen empleo que hizo este último de la arcabucería. Takeda Katsuyori, hijo del famoso Takeda Shingen, lideró el ejército que se enfrentó a las fuerzas combinadas de los Oda y los Tokugawa. La campaña pasó a la historia por el ataque de la caballería Takeda contra una colina plagada de arcabuceros, en un choque entre tradición y modernidad que acabó en sangrienta masacre.

Después de haber experimentado con diversas formaciones, Nobunaga acabó encontrando la clave para contrarrestar el ímpetu devastador de la caballería Takeda. En primer lugar, eligió apostar a sus hombres en la cima de una colina, con lo que la caballería quedaría expuesta al fuego de sus hombres

8. VV.AA., Técnicas bélicas..., p. 53.

9. TURNBULL, Stephen, Kawanakajima 1553-64. Samurai power struggle, London, 2003, p. 24. 
mientras atravesaba el campo abierto, y su carga se vería frenada por la pendiente ascendente.

La colina estaba defendida por tres líneas de arcabuceros, que abrían fuego desde sus barricadas de madera. Éstos estaban dirigidos por los teppô taishô (comandante de los mosqueteros), que marcaba los tiempos de retirada, carga y disparo para cada línea, de un modo similar al empleo y disposición de los arcabuceros occidentales. Las líneas de arcabucería estaban, además, protegidas por arqueros, por los yari (lanceros) y la caballería de Oda.

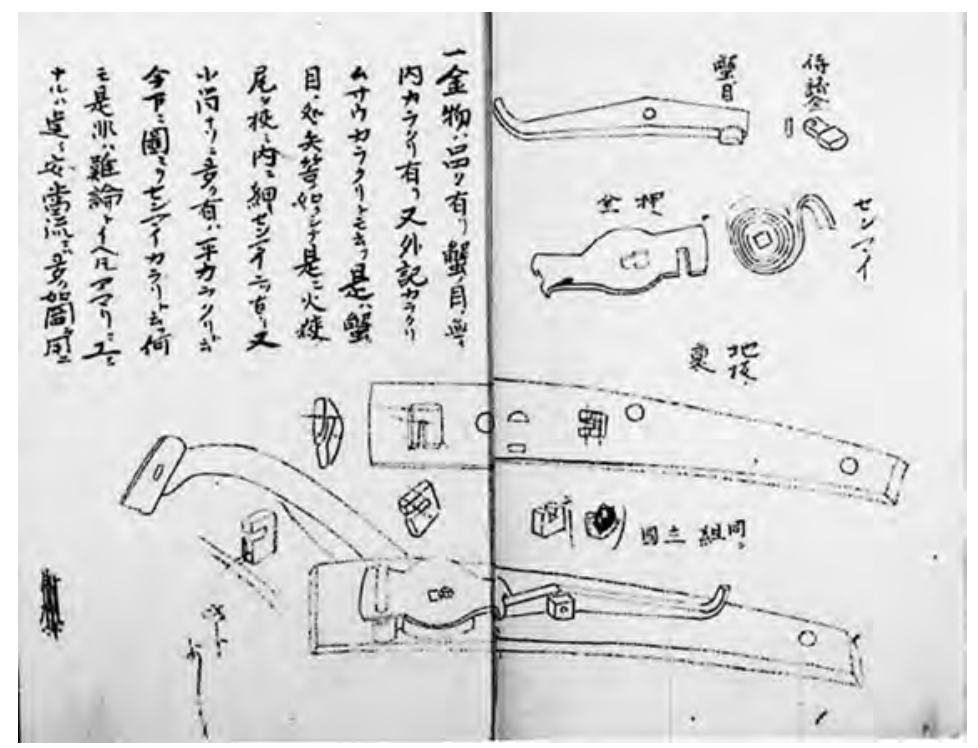

Página de una guía japonesa para la fabricación de los teppô.

Fuente: http://www.rekihaku.ac.jp/e-rekihaku/114/index.html. Consultado el 25/05/2011.

El ejército Takeda, preparado a la manera tradicional japonesa, realizó varios ataques frontales intentando tomar la colina, exponiendo sus hombres a campo abierto. Antiguas crónicas de la batalla narran que Katsuyori ideó la carga atendiendo a las predicciones meteorológicas, que apuntaban a que el día del enfrentamiento llovería. El comandante dio la orden con la esperanza de que al amanecer el cielo amenazaba Iluvia y ésta inutilizaría la pólvora; sin embargo, un sol radiante fue el testigo de la muerte de alrededor de 10.000 soldados Takeda ${ }^{10}$. Estos últimos estaban provistos de las típicas armaduras samu-

10. BRYANT, Anthony, \& McBRIDE, Angus, Samurai (1550-1600): weapons, armour, tactics, 1988, London, P. 57. 
ráis, muy ligeras y aptas para permitir una óptima versatilidad en los combates cuerpo a cuerpo, pero inútiles para los impactos de bala.

En Nagashino quedó constatado que el empleo inteligente de la arcabucería podía dar grandes resultados. En adelante, Nobunaga continuó conquistando territorios y aplastando clanes rivales con la inestimable ayuda de sus arcabuceros. Las fábricas japonesas continuaron creciendo, aunque los daimios tampoco dejaron de contratar con los portugueses ni de recibir con los brazos abiertos cualquier innovación o ingenio que pudiera llegar del otro lado del planeta.

\section{Jesuitas traficantes de armas}

A mediados del siglo XVI existía en Extremo Oriente un triángulo comercial cuyos vértices eran Siam (antiguo reino que comprendía parte de los territorios actuales de Tailandia, Camboya y Laos), China y Japón. Los portugueses fueron los encargados de enlazar y dinamizar el comercio entre distintos reinos desde la factoría de Macao en China, un mercado en el que se intercambiaba pimienta, armamento, azufre, pieles y plata a cambio de arroz, seda, ropas y salitre ${ }^{11}$.

Lógicamente, quienes más se beneficiaron de este trato fueron los daimios cristianos. Numerosos señores feudales, especialmente aquellos cuyos reinos estaban situados en la franja costera meridional, pronto comprobaron que admitiendo la predicación del cristianismo en sus tierras, en las naves portuguesas no sólo iban predicadores, sino también comerciantes con interesantes mercancías. Además, la dedicación de los misioneros reportaba más beneficios que los derivados de la salvación de las almas. Con el paso del tiempo los jesuitas se convirtieron en unos intermediarios formidables para las transacciones entre portugueses y japoneses por dos motivos fundamentales: el conocimiento de la lengua nipona y los contactos que tenían con la gente poderosa. Esto fue así especialmente a partir de 1580, en que Omura Sumitada (conocido en las fuentes occidentales como don Bartolomé), daimio cristiano del Kyushu, cediera a la Compañía de Jesús la ciudad de Nagasaki y el pequeño puerto de Mogi ${ }^{12}$.

Para entonces, Oda Nobunaga ya había muerto, y quien había sido su fiel servidor en vida, Toyotomi Hideyoshi, continuaba la labor de unificación iniciada por Nobunaga, alzándose al cabo de unos años con el poder casi absoluto de Japón, aun por encima del mismo emperador. Hideyoshi mantuvo los contactos iniciados por su predecesor con los portugueses y frecuentó las iglesias y seminarios cristianos. Tomó gran confianza con algunos de los misioneros, invitando a algunos de ellos a su recámara personal en la fortaleza de

11. MASSARELLA, Derek, A World Elsewhere. Europe's Encounter with Japan in the Sixteenth and Seventeenth Centuries, New Haven \& London, 1990, p. 39.

12. Archivum Romanum Societatis lesu, Japonica-Sinica, 23, f. 9. Copia de la donación que hizo don Bartolomé, señor de Omura, de los lugares de Mogi y Nagasaki. S.f. 
Osaka $^{13}$, tratando de asuntos mundanos y de cuando en cuando, algún asunto espiritual. De hecho, él mismo afirmaba que no era ya cristiano porque era un mujeriego incapaz de cumplir el sexto mandamiento.

Los jesuitas participaban del comercio como un medio más de financiación de la misión, aunque algunos de los misioneros no tuvieron escrúpulos a la hora de convertirse en tratantes de armas o esclavos. Éste fue el caso del padre Viceprovincial Gaspar Coelho, quien atrajo al cristianismo a numerosos señores muy poderosos de Japón a cambio de bienes terrenales o mediante sobornos. Pero este trato, del que el mismo Toyotomi Hideyoshi se benefició alguna vez, acabó por levantar sospechas acerca de las intenciones reales de los jesuitas hasta el punto de que en 1588 decretó la expulsión de la Compañía de los reinos del Japón, una decisión cuyas causas aún hoy son muy discutidas por la historiografía, y que en la época despertaron una marea de comentarios y opiniones.

En 1604 se envió al Papa Clemente VIII y a Felipe III un sumario sobre los procedimientos de los padres de la Compañía de Jesús en la India y en Japón. En él, se apuntaba al tráfico de armas que estaban llevando a cabo los jesuitas como una de las principales causas de la expulsión de los padres de Japón el 29 de julio de 1587. Concretamente, los puntos 3 y 4 decían así:

“3, Que os ditos padres da companhia tem no Jappão almazem de arteIharía e arcabuzes de que os gentíos se escandalizão, e o Rey da China os tem por iso em menos conta e se teme delles vendo-os com armas, e esa foi outra caussa pera os lançar fora do Japam.

4, Que tem huma grande fusta de feição de gualle sua propia armada de artelharía grosa, e homens e hum padre por capitão de que tambem ha escandalo"14.

Desde la Compañía nunca se negó la posesión de un arsenal en Nagasaki, y que éste era bien conocido por todos. Alegaban que era necesario en caso de que tuvieran que defenderse en caso de que se vieran afectados por uno de los constantes conflictos que sacudían el país. En cuanto al cuarto punto, se refiere al último gran escándalo que protagonizó el padre Coelho. El capitán Diego de Solís explicaba así el incidente de la fusta y la entrevista con Hideyoshi:

"Había siete años poco más o menos que siendo viçeprovinçial de la Compañía de Jesús en los rreynos de Xapón, el padre Gaspar Cuello, fue a bisitar al emperador Coambaco [Hideyoshi] que aora es, en una fusta muy bien adereçada con pieças de artillería, la qual contentó tanto al dicho emperador que se la alabó mucho al padre Gaspar Cuello que yba en ella. A lo qual, el dicho

13. FROIS, Luis (S.I.), História de Japam, Lisboa, 1984, Vol. IV, p. 227-228.

14. A.G.I., Fil., Leg. 4, N. 4. Decreto de Lerma a Lemos sobre religiosos de Japón por Filipinas. 1604-11-27. 
padre rrespondiá que le diese las tierras y pueblos de Sicafori [...]. El Cuambaco, enfadado de esto, volbió el rrostro a otra parte sin hablar más en la materia y desde a pocos días embió a mandar al dicho padre que él y los demás padres teatinos se fuesen de Xapón todos, que no quería que huviese xpiandad ni aquella rreligión en él y les mandó derribar las yglessias" ${ }^{\prime 15}$.

Otro testigo del mismo proceso, de nombre Marco Antonio, relató la intervención de los jesuitas en las guerras que hubo entre el daimio de Arima y el de Figen, "el qual Alimandono [señor de Arima] por ser xpiano ayudaron con una fusta que tenían los padres armada con gente y buena artillería, e que por la ayuda que tubo en los dichos padres no se pudo vengar de él el dicho rrey de Fixen, e assí volbió e conçibió odio mortal contra los dichos padres y se determinó de perseguirlos, y a la xpiandad de aquel rreyno". Afirmaba este testigo que el señor de Figen insistió a Hideyoshi para que echara de Japón a aquellos religiosos que podían ser un peligro potencial, y "por estas y por otras causas el Cuambaco mandó derribar las yglessias, particularmente las que eran fuertes e tenían artiIlería". Este mismo testigo pudo ver "por sus ojos la dicha fusta de los padres armada e articulada e sabe que los padres teatinos son mercaderes en gruesso e que por esto y por las muchas tierras e mayorazgos que tienen y ocupan y la potençia y authoridad que trahen son odiossos al Cuambaco"16.

En el mes de julio de 1587, el padre Coelho había concertado una entrevista en Hakata con Hideyoshi para hablar de ciertos asuntos importantes que habían quedado pendientes la última vez que ambos se habían reunido. El padre acudió a la misma con una fusta, un pequeño buque de guerra bien pertrechado, que causó sensación en la zona. La fusta fue durante una semana un trasiego de gente, entre curiosos, cristianos que venían a escuchar la predicación y soldados que querían echar un vistazo al barco. La fama de la nave llegó a oídos de Hideyoshi, quien quiso visitarla sin siquiera avisar al padre. Con una mezcla de asombro y miedo, recorrió todos los rincones de la fusta, sopesando las posibilidades de todas aquellas armas y municiones, muchas de ellas nunca vistas hasta entonces en Japón. En cuanto se marchó de allí, algunos daimios cristianos (Agustín Yukinaga, Justo Ukondono) corrieron a decir al padre Coelho que cediera la fusta de manera inmediata a Toyotomi Hideyoshi ya que, si no se la regalaba, Hideyoshi podía tomarse el paseo del padre con la fusta como una soberbia exhibición del poder militar que estaban acaparando los cristianos.

Aunque finalmente Coelho donó la fusta a Hideyoshi, ya era demasiado tarde. Las sospechas que podía albergar el caudillo militar, aumentadas por los enemigos que los padres tenían en Japón, muchos de ellos del entorno de Hide-

15. A.G.I., Fil., Leg. 6, R. 7, N. 103. Testimonio sobre envío de embajada de franciscanos a Japón. 1593-06-10 (Manila).

16. A.G.I., Fil., Leg. 6, R. 7, N. 103. Testimonio... 
yoshi acabaron desembocando en la tajante decisión de expulsar a los jesuitas de Japón apenas 24 horas después de haber inspeccionado la fusta. Aunque el decreto de expulsión no aludía directamente el incidente, no faltó quien ató cabos y relacionó la animadversión de Hideyoshi hacia los jesuitas con las actividades que estaban desarrollando los padres, inmiscuyéndose en asuntos demasiado terrenales para su oficio.

El asunto había sido denunciado por numerosos padres, que también se mostraban alarmados por los peligros que conllevaba el tráfico de armas, suministradas sobre todo a los daimios cristianos para que defendieran sus reinos de las incursiones de daimios infieles ${ }^{17}$. El profesor Álvarez Taládriz rescató un documento del Archivo Romano de la Compañía de Jesús que explica las acciones del padre viceprovincial de la Compañía Gaspar Coelho ${ }^{18}$. En él, el padre Organtino denunciaba ante Aquaviva que "il procedere del nostro superiore Coeglio in questa conversione è piu presto di capitanio d'armi che di pastore d'anime [...] e forse che por questa causa stiamo in questa tribulatione ${ }^{\prime \prime 19}$. Si bien Organtino también admitía que probablemente el padre Viceprovincial hiciera aquello con la mejor de las intenciones, entendiendo que ayudando a los daimios cristianos también ayudaba a que la cristiandad tuviera una tierra segura donde acudir en caso de persecución, e incluso llega a reconocer que si sus planes hubieran tenido un éxito completo, nadie habría cuestionado su proceder.

En aquella misma misiva recordaba el padre Organtino que unos años atrás, en mayo de 1586, Hideyoshi les había invitado a él, al padre viceprovincial y al padre Luis Frois a visitar las obras de la fortaleza de Osaka. Ahora recordaba Organtino que durante la entrevista Hideyoshi les confesó sus intenciones pasar a conquistar China y Corea, a ser posible con el apoyo logístico que pudieran proporcionarle los padres, a lo que Frois le contestó que para eso contara con la ayuda del padre Coelho, quien podría suministrarle embarcaciones y armamento $^{20}$. A cambio, Hideyoshi prometía a los padres que él mismo se encargaría de impulsar el cristianismo en los reinos conquistados, y de darles renta y construir iglesias allí. Frois, que actuó como intérprete en aquella ocasión, parece haber olvidado sus propias palabras cuando describió los pormenores de la entrevista en su Historia de Japón:

"Tendo elle chegado àquelle estado e sugeito a sy todo Japão, não pertendia já reynos, ouro nem prata, de que tinha grande abundancia, nem

17. A.R.S.I., Jap. Sin. 11, I, f. 22. Mexía, Macao, 22-XI-1588; A.G.I., Filipinas, Leg. 6, R. 7, N. 103. Testimonio sobre envío de embajada de franciscanos a Japón. 1593-06-10, (Manila).

18. ÁLVAREZ TALÁDRIZ, José Luis, "El padre viceprovincial Gaspar Coelho, ¿capitán de armas o pastor de almas?", Sapientia, Eichi University, no 6, 1972, Osaka, pp. 41-79.

19. A.R.S.I., Jap. Sin. 11, I, f. 66v, Organtino a Aquaviva, 10-XI-1589 (Nagasaqui). La cursiva es mía.

20. A.R.S.I., Jap. Sin. 11, I, f. 70r, Organtino a Aquaviva... 
outra couza alguma mais, que deixar quando morresse nome e fama de seo poder. E que determinava consertar as couzas de Japão de maneira que tomassem assento, e que feito isto, o entregaria a seo irmão Minodono e elle entenderia na conquista dos reynos de Corea e da China, e que para isso mandava cortar madeira para della fazer duas mil embarcações, em as quaes passasse seo exercito. E que para sua pessoa não queria outra ajuda dos padres mais que negociarem-Ihe duas naos grandes bem aparelhadas, as quaes tão pouco queria de graça, senão pagándo-las e todo necessário para ellas... E se lhe sucedesse bem e os chinas se lhe viessem sugeitar e dar a obediência, não queria delles outra couza, nem havia de ficar lá nem tomar-lhe suas terras, mais que sugeitá-los a seu império; e que então levantaria em todas as partes igrejas e mandaria que todos se fizessem desta nossa ley, e assim se tornaria para Japão. E dizendo mais que ainda havia de fazer christãos a metade ou a mayor parte de Japam" ${ }^{21}$.

Con la muerte del padre Coelho se hicieron públicos todos sus negocios, que tenía anotados en diversos papeles que guardaba en su escritorio. El padre visitador Alesandro Valignano tomó la pluma para advertir al padre General en Roma de las acciones que había estado llevando a cabo el Viceprovincial de la Orden, y sus palabras no dejan lugar a dudas:

"Il negotio fue ch'il padre Gaspar Coeglio pigliando occasione delle continue guerrre che passorno quest'an a dietro nelle quali li signori d'Arima \& d'Omura e il re Francesco di Bungo, si vedder in molti pericoli con il zelo ch'il padre teneva che si conservassero in queste guerre se fu mettendo tanto in quelle sotto spetie d'aiutarli che fece imprudentie \& indiscritioni molto grandi, \& fra l'altre fu persuadire Quambacudono [Hideyoshi] perce venisse in questo Ximo ["siete reinos", isla de Kyushu] a sugettare Riozogi \& il re de Sazzuma, promettendogli che gli faria così con il re Francesco di Bungo, come con il re d'Arima \& altri signori christiani, che tutti insieme s'unissero \& facessero di sua parte. \& paredogli che qanto più mostrasse a Quambacudono che li patri lo potriano aiutare in diversa sue trazze, veme a termine che dicendo gli Quambacudono che dipoi de conquistato Giappone haveva dipassare alla Cina, parendo al padre che ciomai sarebbe \& che gli guadagnaria la voluntà mostrando gli ch'ancora in questolo potria aiutare gli disse che quando volesse passare alla Cina gli faria havere due navi portughese \& faria con il vicere dell'India che gli mandasse gente per aiutarlo. \& come Quambacudono è sagacissimo, mostrava di contentarsi molto con questo che gle diceva facendo gli molti favori \& carezze ma nel suo intrinseco comencio a concepire che poscia che questo patre teniva tanto potere con li signori xpiani, che faria d'essi quello che volesse, \& era tanto

21. FROIS, Luis (S.I.), História, Vol. IV, p. 229. 
ricco che gli potria dar due navi per passare alla Cina \& si metteva nelle guerra, potria un giorno far quello che fece un bonzo, che chiamano qui Osacca $^{22}$, che di por d'aggiuntar molata gente di Giappone a sua setta si fece signore di tre regni \& mosse guerra crudele contra Nobunanga, che fue la piu lunga \& travagliosa ch'egli temhebbe \& che noi altri potriamo fare questo molto migliore, perche facevano molto grandi signori christiani, con li quali gli potriamo un giorno fare grande guerra \& procurare di farsi signore della Tenca, (id est monarchia di Giappone). Ben intesero li patri \& li signori christiani che questo ch'il padre diceva \& prometteva era cosa molt indiscreta \& pericolosa \& non mancarono di diglilo. Ma egli vedendosi tanto favorito di Quambacudono giamai si volte persuadere ch'errava in questo, anzi gli pareva che faceva molto bene \& che da qui se seguiva grande frutto \& creedito così per la xpianità come per la Compagnia. \& perche io previddi in Giappone il male che ci potria fare se d'alcun modo ci mettessimo in queste guerre, lasciai ad litteram quest'ordine [...]. Quando adesso viddero li patri le lettere che si ritrovano nel suo scrittorio rimasero maravigliati perche egli ascondeva queste lettere \& non faceva saper nulla a quelli di sua consulta, oltrecio per poter il detto padre meglio favorire \& aiutare nelle sue guerre questi signori fece fare una fusta \& compro alcuni tiri d'artigliaria contra ordine \& ragione \& stesso iva in persona di qua \& di là con quella fusta" ${ }^{23}$.

Tras el edicto de expulsión de 1587, los jesuitas tuvieron que vivir escondidos en Japón. Aunque nunca fue revocado, los misioneros pudieron continuar su labor gracias a su proceder discreto, tratando siempre de no dar ningún motivo a Hideyoshi para que renovara sus sospechas hacia los cristianos. Parece ser que los padres dejaron de inmiscuirse en guerras, tal como recomendó el padre visitador Valignano, o al menos no llegó a hacerse público ninguno de estos posibles tratos. Pero la ambición de Hideyoshi era insaciable, y sus planes de conquista pasaban por la adquisición del armamento más desarrollado del momento. Una vez que los hombres de Dios cesaron en su labor de proveedores, los españoles de Manila aparecieron como una interesante baza a explotar, ya fuera por las buenas... o por las malas.

\section{El comercio de armas entre Japón y Filipinas}

Sin tener en cuenta la actividad ilegal, el tráfico mercantil oficial entre Filipinas y Japón resultó ser muy fluctuante. En la gráfica que ofrecemos a continuación se aprecia el número de barcos japoneses que llegaron a la capital filipina desde que en 1591 Hideyoshi diera permiso para este trato.

22. El tan citado "bonzo de Osaka" al que se refieren las relaciones cristianas, Kennyo Shonin o Honganji Koza ( $i$-1592).

23. A.R.S.I., Jap. Sin, 11,II, f.233 y ss. Carta de Valignano al general Aquaviva avisando de los procedimientos del difunto padre viceprovincial Gaspar Coelho. 14-X-1590 (Nagasaki). 
Número de barcos japoneses con sello oficial que llegaron a Manila entre 1591 y 1611.

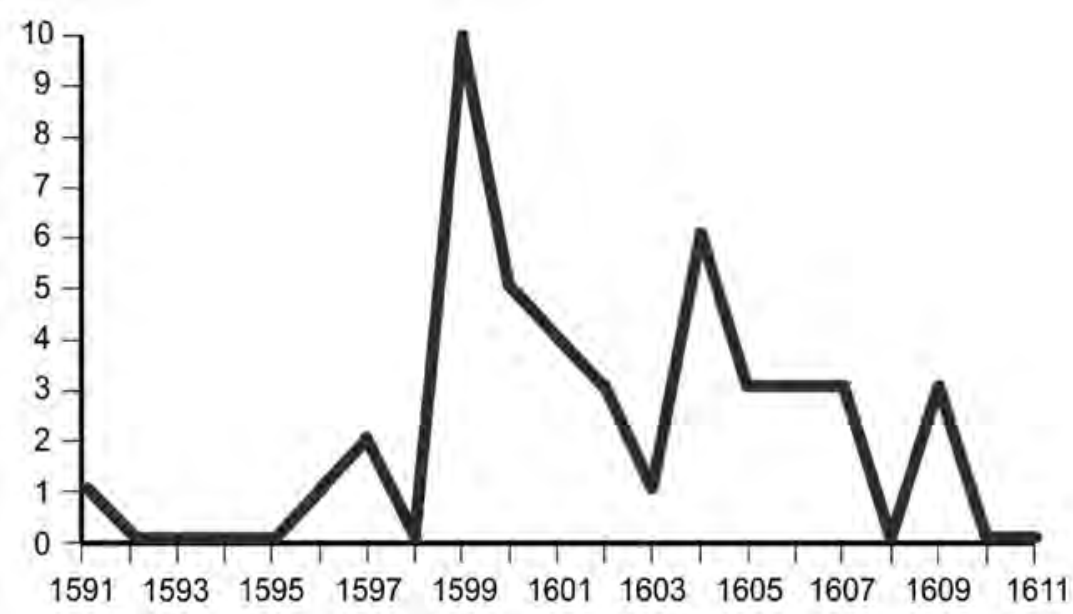

Fuente: elaboración propia a partir de datos ofrecidos por el profesor Chaunu, citados en SOLA CASTAÑO, Emilio, Relaciones entre España y Japón, tesis doctoral inédita dirigida por d. Vicente Rodríguez Casado, Madrid, 1971, p. 28.

Aunque no puede especificarse con exactitud, debido a que las actividades contrabandísticas y la actividad de los wako escapaban a las cifras oficiales, la gráfica aporta una idea general sobre este intercambio. Destaca el pico alcanzado en 1599, con la llegada de diez barcos japoneses a Manila, y la relativa regularización a partir de 1605, con tres barcos anuales controlados ya por el sogún Tokugawa Hidetada. Aunque no aparezca en la gráfica, hay que reseñar que la arribada de naves japonesas se congeló en el periodo que va de 1610 a 1619 , años durante los cuales no legó ninguna nave japonesa. En 1620, de nuevo, volverán los tres barcos anuales, pero ya quedaba muy poco para que el sogún decretara el sakoku, poniendo fin a este comercio. El estudio detenido de la documentación española puede añadir algún detalle más, aunque en modo alguno lograr una precisión total. Durante la gobernación de Pedro de Acuña (1602-1606), se estableció una nave anual que fuera de Manila a Japón, pero lo normal es que fuera acompañada por otras: "con la nao que esa Audiencia (de Filipinas) suele despachar cada año al Japón suelen ir otras tres o cuatro de particulares, de manera que hay contratación en forma" ${ }^{24}$.

Aparte de la plata, interés principal de los españoles en el comercio con Japón, se aprovechó el trato con Japón para conseguir los bastimentos necesa-

24. A.G.I., Fil., Leg. 329, Tomo II, fo 97. Carta del rey a don Juan de Silva, de 25-VII-1609. 
rios para Manila a muy buen precio, tales como alimentos, minerales, armas o textiles. Morga, en su Historia de Filipinas, transmite cuáles eran los productos que normalmente venían de Japón: cáñamo para jarcia, cobre, hierro, acero, salitre, mantas, pólvora, clavazón, armas (catanas, municiones, armas enastadas), trigo, harinas, jamones, atún, cecina, etcétera. De las islas filipinas los japoneses levaron a su tierra, en primer lugar, la seda que los comerciantes chinos vendían en el archipiélago español; este comercio de la seda y otras mercancías de China fue fundamental en el trato con los japoneses.

El principal producto era la seda china, intercambiada por plata nipona, seguida de armamento y madera de suou (Caesalpinia sappan). Desde Manila dejó de exportarse armamento a Japón, para importar municiones, harina y catanas. En cuanto al volumen de este comercio, en la documentación se puede encontrar alguna referencia. Así, en 1592 se dan cifras concretas al citarse la carga de un navío pequeño que Ilegó a Manila procedente del puerto japonés de Hirado. Dicho barco traía "400 picos de harina y 30 de cobre", lo que equivale a unas 25 toneladas $(25.304,8 \mathrm{~kg})$ y casi dos toneladas $(1.897,86 \mathrm{~kg})$ respectivamente; traía además, 1.600 mantas y 150 catanas $^{25}$.

Pasemos a calcular ahora en valor monetaria ese volumen de intercambios, con la referencia de la grave pérdida del galeón San Felipe, que iba camino a Nueva España cuando se perdió en las costas japonesas. Según algunos cálculos, el extravío del galón supuso para los habitantes de Manila la pérdida de un millón o un millón y medio de pesos ${ }^{26}$. Esta cifra era el equivalente de los intercambios luso-nipones en un año, teniendo en cuenta que el volumen total de comercio portugués con Japón estaba a la altura del año 1606 estimado en alrededor de un millón y medio de pesos que se obtenían a través de las ganancias del galeón de Macao $^{27}$. En todo caso, el volumen de intercambio comercial se vio incrementado notablemente durante los primeros años del gobierno de Tokugawa leyasu.

A finales del siglo XVI, el tráfico de armas de fuego era constante, como demuestra la arribada de un barco japonés a Manila en 1589, que transportaba más de 500 arcabuces con la presunta intención de venderlos ${ }^{28}$. Desde Manila tampoco interesaba que el Japón estuviera fuertemente armado, ya que las defensas de las islas Filipinas eran precarias y la amenaza de que Toyotomi Hideyoshi decidiera emprender la conquista de las islas era cons-

25. A.G.I., Fil., Leg. 18, Ramo 5, N. 125. Informe testifical hecho en Manila ante las sospechas de invasión que se tuvieron en la ciudad. 20-IV-1592 (Manila).

26. A.G.I., Fil., Leg. 163, R. 1, N. 1. Copia de un capítulo de carta que la Audiencia de Manila escribió a Su Majestad en 8-VII-1608 (Manila).

27. Archivo General de Simancas, Estado, Leg. 2637. Consulta del consejo de indias. 30-V1606.

28. A.G.I., Fil., Leg. 18A, R.7, N.49. Carta del fiscal de la audiencia de Manila Gaspar de Ayala sobre situación general. 1589-07-15 (Manila). 
tante. Si el japonés hubiera tomado la decisión, auspiciado por los informes que le escribía Harada Mangoshiro desde Manila, se hubiese encontrado con unas tierras pobremente defendidas. Escribía el gobernador Tello en 1598 que acababa de construir una fortaleza "inexpugnable" con capacidad para 1.000 hombres armados. El problema era que la gente que se enviaba desde Nueva España era "inútil y en su mayor parte desarmada", por lo que pedía que trajeran de España 800 arcabuces y 400 mosquetes. De paso, aprovechaba para informar que estaban fundiendo piezas de artillería gracias a un invento de los chinos que vivían en el Parián de Manila, y que hecha la fundición, no dejaría marchar a los sangleyes de nuevo a China ${ }^{29}$.

Pero en lugar de atacar las Filipinas, Hideyoshi quiso que la historia le recordara como el hombre que conquistó Corea y China. Las relaciones entre Japón y Filipinas durante aquellos años que duró la guerra de Corea (1592-1598) fueron de continua sospecha, un tiempo de embajadas y enorme precaución política. Escribía el capitán Pedro González de Carvajal acerca de la situación y cómo podría aprovecharse en beneficio del rey y de la religión:

"Notorio es que el emperador del Japón es poderoso de gente y armas, y que su gente es de mucho ánimo, el qual quedaba aprestando doscientos navíos y fundiendo cantidad de artillería, y que está distante del reyno de las Philippinas quatrocientas leguas, que es camino de quinze a veinte días por mar = Depende de su amistad la conservación de las Philippinas y de docientos mil christianos que están en el mismo reyno del Japón, y ansimismo de los demás que cada día se van christianando = Tiénense grandes esperanças de que todos se han de bolver christianos, porque se sabe averiguadamente que mucha gente principal del Japón se bolverían cristianos, si no se lo estorbase el rezelo que tienen de la indignación del dicho emperador = El qual me mandó deçir a V. M. que haziendo V. M. buena amistad con él daría al gobernador de las Philippinas siempre que fuesse menester socorro de diez mil hombres = Quando el gobernador de Meaco [Kyoto] (que es la persona que gobierna todo aquel reyno) me entregó la carta que a V. M. traigo, me dixo que dixesse a V. M. como el emperador era su amigo y que de su parte no faltaría la amistad y que esto no lo tuviesse V. M. en poco por estar lejos [...]. Conviene mucho que V. M. embíe cédula al obispo de la gran China de Macán y a los padres de la Compañía de Jesús, para que todos los navíos que de allí partieren y pasaren para el Japón, se visiten y miren que no lleven gente alguna de quien se tenga muy buen concepto de xpiandad y fidelidad: porque aquel emperador anda desseoso de topar personas que le enseñen a hazer navíos al modo nuestro y artillería:

29. A.G.I., Fil., Leg. 6, R. 9, N. 144. Carta de Tello sobre abandono de Mindanao, embajada a Japón. 1598-06-17, (Manila). 
porque todo esto sería de grandíssimo daño y inconveniente: que aunque tiene artillería y navíos, no son de tanto effecto como los nuestros ${ }^{\prime 30}$.

Todas las precauciones no fueron suficientes para evitar que el potencial bélico de Hideyoshi se incrementara con la adquisición de piezas occidentales, y en 1597 recibió un regalo arrojado por el mar a la costa de Tosa: el galeón San Felipe. Era éste uno de los galeones de Manila que hacía todos los años el recorrido Manila-Acapulco cargado con materiales de gran valor, plata japonesa, artículos de lujo de China, especias...y todas las piezas de artillería y arcabucería necesarias para defenderlo de cualquier ataque (de cualquiera excepto de la furia del Mar de Japón, que destrozó el barco y dejó desamparados tripulación y cargamento).

Pero ni siquiera con este extra logró tener éxito Hideyoshi: ni los arcabuces de Sakai, ni las armas robadas a los españoles, ni la tecnología europea más avanzada que había llegado a las islas niponas, pudo con los barcos de guerra coreanos que, acostumbrados desde antiguo a convivir con la pólvora, habían evolucionado hasta dejar impotente al ejército naval japonés de la época.

Los coreanos combatieron en el mar con una suerte de barcos acorazados, un ingenio del gran comandante coreano Yi Sun-Sin, que a bordo de la famosa nave Kwi-son o Barco-tortuga, causó estragos en la flota japonesa en 1593. El barco era una especie de galera en cuyos laterales se disponían filas de soldados que quedaban a cubierto del fuego enemigo gracias a unas planchas con recubrimiento metálico. Se dice que con esta única nave y gracias a una táctica de cebo y retirada semejante a la que usaban los mongoles en tierra, consiguió hundir 70 naves japonesas, que fueron sucumbiendo una a una ante la defensa total del Kwi-son ${ }^{31}$.

Hideyoshi volvió a intentarlo en 1597, pero de nuevo el ejército japonés fue repelido por una combinación de tropas chinas y coreanas. En esta ocasión, el ilustre Yi tuvo la mala fortuna de recibir el impacto mortal de una bala disparada por un soldado japonés que aprovechó la retirada del coreano.

Finalmente, los japoneses hubieron de retirarse de Corea, que contó con el respaldo del ejército chino para repeler a los nipones. La guerra se saldó con cuantiosas pérdidas en ambas armadas, pero sobre todo entre la población civil de la península coreana, y además sirvió para que los dirigentes japoneses confirmasen que estaban muy lejos de dominar la técnica militar naval como para hacerse fuertes en las aguas circundantes. Por ello, continuaron en su afán de conseguir constructores de barcos y artilleros europeos -a lo que los castellanos

30. A.G.I., Fil., Leg. 6, R. 7, N. 110. Carta de Pedro González de Carvajal sobre su viaje a Japón, 1594.

31. STORRY, A History..., p. 53. 
se opusieron en rotundo-, y en sacar provecho de los numerosos naufragios que dejaban en bandeja de plata arcabuces, municiones y cañones pesados, para mayor gloria del sogún.

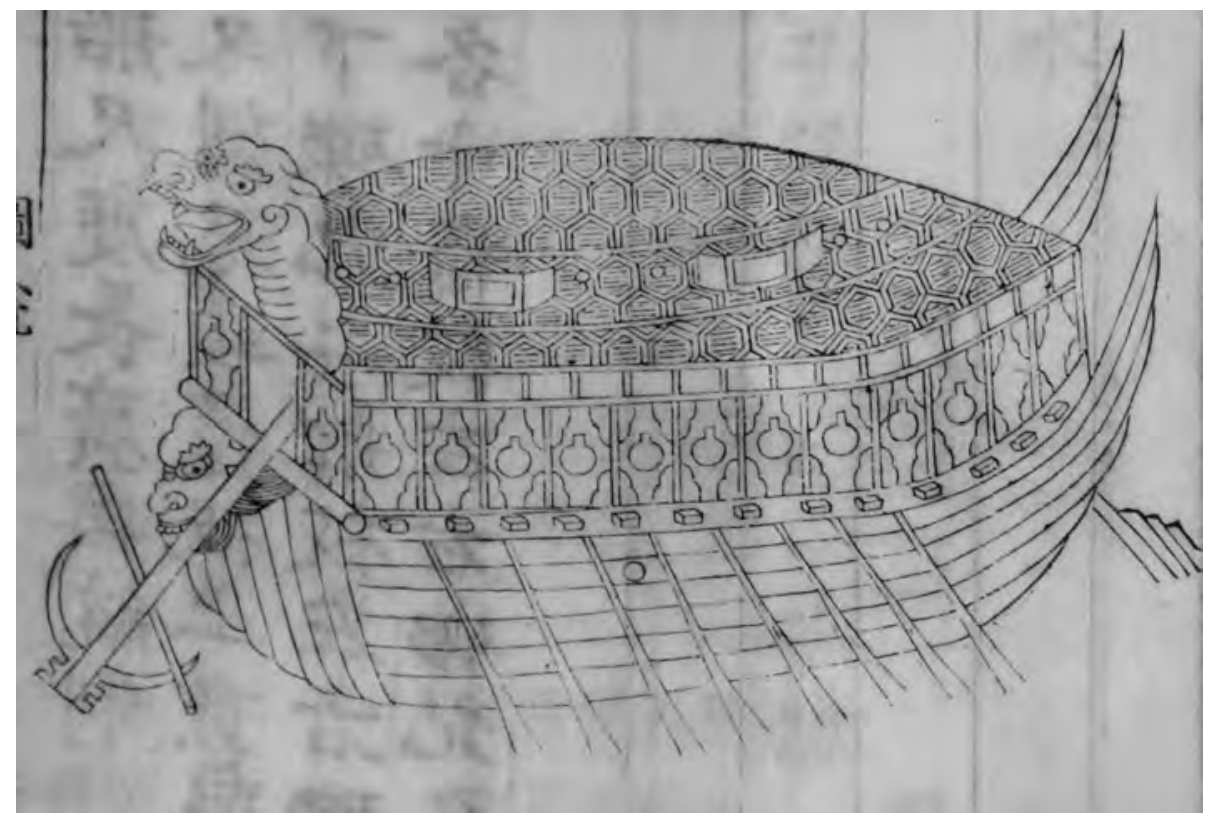

Barco tortuga coreano empleado en la guerra entre Corea y Japón (1592-1598). Fuente: http://www.themanyfacesofspaces.com/MFS-StrangeButTrue-ThingsOther20.html. Consultado el 25/05/2011.

\section{El empleo de la artillería pesada}

Mucho antes que la llegada de los arcabuces occidentales, en Extremo Oriente ya se usaba varios artefactos que empleaban la pólvora, además de las pistolas chinas ya mencionadas. Los proyectiles incendiarios y explosivos (tales como bombas de fragmentación o lanzallamas), usados sobre todo en acciones de asedio y batallas navales, están documentados en China desde el siglo IX ${ }^{32}$, y una suerte de obuses de fábrica china fueron utilizados en Japón en el siglo $\mathrm{XV}^{33}$. Sin embargo, la fabricación de cañones en China sólo se vio impulsada con la aplicación de tecnología portuguesa de retrocarga.

32. En este siglo está datada la invención de la pólvora por los chinos.

33. VV.AA., Técnicas bélicas..., p. 63. 
Como había pasado con el San Felipe, Tokugawa leyasu pudo hacerse con la hacienda que llevaba el Liefde, un barco holandés que naufragó en Bungo en abril del año 1600. leyasu confiscó todo el armamento de la nave, a saber, 50 cañones de gran calibre, 500 arcabuces, 5.000 cañones pequeños, 50 quintales de pólvora y 350 flechas incendiarias ${ }^{34}$, botín que le resultó muy útil en la bataIla de Sekigahara que tendría lugar en octubre de ese mismo, y en la que consiguió una victoria aplastante sobre sus rivales, que le encumbró a la cima del poder político en Japón.

Desde Manila observaban este trasiego de artillería pesada no con poca preocupación, dando noticia de ello la carta del gobernador Pedro de Acuña, fechada en 1602, en la que narra que aun con "los pocos que son [ingleses y holandeses] se ha valido [leyasu] en una guerra que tubo este año passado con un rey que no le quería obedezer y llevó algún artillería industriado de ellos y suçedióle bien la jornada" ${ }^{\prime 35}$.

En Filipinas tampoco perdían la oportunidad de sacar partido de este comercio. Así, el gobernador Pedro de Acuña escribía al virrey de Nueva España, el marqués de Montesclaros, que en 1605 había encargado comprar en Japón 1.200 balas para las cuatro piezas de artillería con que contaba en Manila, supliendo de alguna manera la falta de hierro que había en las islas a consecuencia de la prohibición de la venta de este metal en China, de donde se importaba ${ }^{36}$. Unos años más tarde, en 1632, el gobernador Niño de Távora informaba que de Japón también se importaba cobre $^{37}$, causa por la que se prohibió este comercio en el año 1641 por orden del emperador de Japón, quien albergaba la sospecha de que este tráfico favorecía a los daimios cristianos ${ }^{38}$.

El ejército japonés se acostumbró en pocas décadas al empleo de las nuevas tecnologías. Los hombres de Tokugawa llegaron a ser muy diestros en el uso de las armas de fuego, tal como escribe el padre Valentím Carvalho en una carta del año 1612: "o senhor da Tenca he oje em dia tam poderoso que pode ajuntar fáçilmente quinhentos mil homens de peleja: todos muito bons soldados e mosqueteiros que nam erram baluo" ${ }^{\prime 39}$.

34. TURNBULL, Stephen, Osaka 1615: The last battle of the samurai, Osprey, New York, 2006.

35. A.G.I., Fil., Leg. 19, R.3,N.47. Carta de Acuña sobre su viaje y gobierno, 11-VII-1602 (Manila).

36. A.G.I., Fil., Leg. 29, № 83, ff 523 r 530v, Carta de Acuña al virrey sobre varios asuntos, 1-VII-1605 (Manila).

37. A.G.I., Fil., Leg. 8, R. 1, N. 16. Carta de Niño de Távora sobre expulsión de holandeses. 8-VII-1632 (Manila).

38. A.R.S.I., Jap. Sin. 22, f. 314 y ss, Averiguación de las causas que provocaron la proscripción del cristianismo en Japón. 1641 (Macao).

39. A.R.S.I., Jap. Sin 15, II, f. 178. Carta de Carvalho a Aquaviva, 26-X-1612 (Nagasaki). 
El licenciado Juan de Cevicos pone el acento en la habilidad de los japoneses, avisando que eran "gente de armas, en cuya bondad y aseo ponen particular cuidado", muy hábiles en el uso de los "arcabuces, cuya puntería son tan diestros que matan la caça". Pero también da noticias de sus fortificaciones: "Tienen algunas fortaleças con fosos y prevençiones que para no aver como ay en este rreyno artillería con que sitiarlas, parecen ynespunables" ${ }^{40}$.

Para principios del siglo XVII el empleo de la arcabucería ya se había extendido por prácticamente todos los ejércitos de los daimios, pero Tokugawa leyasu tenía una ventaja sobre sus rivales: la artillería pesada, introducida en Extremo Oriente por ingleses y holandeses. Para la campaña de Osaka, que supondría la derrota definitiva del clan Toyotomi y el afianzamiento definitivo de su apellido en la línea sucesoria sogunal, leyasu adquirió en diciembre de 1614 cuatro culebrinas inglesas, un saker (parecido a la culebrina, pero de menor tamaño) y 10 barriles de pólvora, según un informe enviado por Richard Cocks a la British East India Company ${ }^{41}$. leyasu también había comprado a los holandeses 5 ishibiya (cañones de mano), aunque se estimaba que podía contar hasta con 12 de ellos, si se tiene en cuenta lo que requisó del Liefde. Estos cañones que vinieron a completar la artillería fabricada en Sakai por manos japonesas, como el cañón Shibatsuji, el cañón japonés más antiguo que se conserva. Fue fabricado por Shibatsuji Ryuemon Sukenobu en 1614, con un calibre de $9 \mathrm{~cm}$ y una longitud de $313 \mathrm{~cm}$. Empleado en el asedio de Osaka, hoy se conserva en el Museo Yushukan del Santuario Yasukuni de Tokyo.

Un tipo de cañón, ligeramente más corto, llamado furanki, era la base de la artillería de Hideyori. De factura portuguesa, o fabricados en Goa o Nagasaki bajo supervisión lusa. Quedó demostrada su inefectividad para la defensa del castillo frente a las fuerzas Tokugawa ${ }^{42}$. Los cañones de leyasu quedaban bien lejos del rango de disparo de los furanki más poderosos. El 15 de enero de 1615, los cañones de leyasu bombardearon masivamente el castillo de Osaka, en un terrible espectáculo nunca visto antes en Japón.

Eso sí, fue un espectáculo que sirvió de poco para el resultado final del asedio. Los castillos japoneses estaban diseñados de tal modo que podían resistir cualquier tipo de ataque con armamento de aquella época, con una base constituida por piedras de varias toneladas de pesa. Unos muros capaces de soportar el impacto de una bomba nuclear (tal como pasó con el castillo de Nagasaki en 1945, que sólo sucumbió porque sus pilares resultaron dañados) no fueron suficiente para escapar del poder destructor de los cañones. La parte superior

40. A.G.I., Fil., Leg. 4, N. 6., Carta de Juan Cevicos, capitán y maestre de la nao San Francisco que se perdió el año 1609 en Japón, haciendo una descripción de Japón y exponiendo la necesidad de hacer elección entre Filipinas y Macao para el trato con Japón, 20-VI-1610 (Manila).

41. TURNBULL, Stephen, Osaka..., p. 49.

42. TURNBULL, Stephen, Osaka..., p. 57. 
de los castillos japoneses, donde estaban las dependencias personales, consistían en una estructura de madera. Una bala de cañón destrozó la estancia donde se encontraba Yodogimi, madre de Hideyori, quien, aterrorizada, rogó a su hijo que iniciara las negociaciones de paz con leyasu. Así concluyó la campaña de invierno del asedio de Osaka.

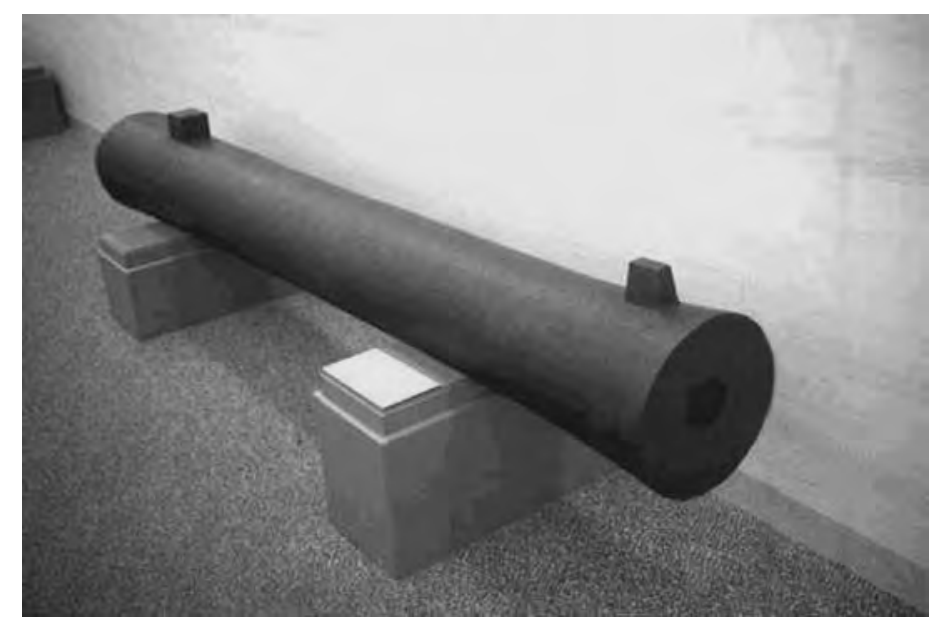

Cañón Shibatsuji, fabricado en 1614. Conservado en el Museo Yushukan del Santuario Yasukuni de Tokyo.

La última campaña bélica japonesa en la que tuvo importancia el empleo de la artillería fue durante la represión a la rebelión de Shimabara en 1641. Ésta se inició cuando un joven destrozó la cabeza de su amo con una azada, harto ya (tanto él como los otros campesinos de la región) de las constantes subidas de impuestos, la imposición de nuevas corveas y un incremento en los precios de los alimentos. Por desgracia para el futuro del cristianismo, se dio la circunstancia de que la inmensa mayoría de los rebelados eran cristianos, por lo que las autoridades japonesas sospecharon que españoles y portugueses podían estar implicados. En la averiguación de las causas que llevaron a la proscripción del cristianismo en Japón en 1641, como consecuencia de la rebelión de Shimabara, se lee lo siguiente:

"O alevantamento dos christãos japões de Arima foi exemplo manifesto de tudo o que os olandezes tinhão dito e foi cauza total da quebra do contrato de Japão, porque posto que os ditos japões christãos não se levantarão por serem christãos senão pollos novos tributtos e vexaçois com que os oprimião, com tuo appelidarão nome de christãos poserão nas bandeiras as imagens sagradas, davãos os asaltos invocando os santíssimos nomes de Jesus, Maria, tomarão huma fortalesa honde se defenderão muito tem- 
po do exérçito do emperador, morrendo de parte e parte mais de oitenta mil homes, athe de todo acabarem os trinta e tantos mil christãos que se levantarão com que ficou o emperador tam asanhado e a ley christam tão odiada que mandou por seus governadores promulgar a sentença da quebra do contrato com Macao" ${ }^{\prime 4}$.

Es más, un testigo morador en Macao declaraba que en la ciudad era muy notorio el rumor (alentado por los holandeses) de que los españoles Ilevaban a Japón "pessas de artelharia pera fazer guerra aos mesmos japões" ${ }^{44}$. Sin embargo, los únicos cañones europeos que se sabe a ciencia cierta que fueron empleados en Shimabara, fueron los disparados desde las embarcaciones holandesas que el sogún contrató para reprimir la rebelión.

\section{Consecuencias de la introducción de armas de fuego en el Japón feudal}

La introducción de las armas de fuego en Japón (entre las que cabe destacar el arcabuz o teppô) revolucionó el panorama nipón tanto en el plano militar, como en el político y social: favoreció la escalada de poder de daimios como Oda Nobunaga, transformó la táctica militar, pero tras el edicto del Sakoku (1641), no se introdujo ninguna innovación en la industria armamentística.

Hasta el siglo XV, la guerra se había desarrollado de una manera tradicional en Japón con un notable peso de la caballería, que continuó especializándose en el arte de la guerra, y durante la era Sengoku consistía ya en una formación de samuráis perfectamente equipados, que dirigían a un gran número de soldados de a pie (que no solían ser otra cosa que campesinos sujetos a duras corveas). Las armaduras pesadas, las espadas, los arcos y la caballería, poco a poco perdieron su importancia en la batalla a favor de armaduras ligeras, picas, alabardas y arcabuces a partir de los años 60 del siglo $\mathrm{XVI}{ }^{45}$. Para combatir a la infantería armada con mosquetes y arcabuces, las tropas de a pie cambiaron el arco por la lanza larga, y los arqueros a caballo se transformaron en piqueros a caballo. Evitando las cargas a campo abierto, se buscaba contrarrestar las armas de fuego con ataques cuerpo a cuerpo.

Los daimios necesitaron incrementar de alguna manera el número de soldados de infantería, que armados con sus arcabuces comenzaban a resultar fundamentales en las batallas. Había dos vías para ello: el uso de levas masivas entre los campesinos de sus tierras y la contratación de hombres sin tierras que precisaban algún tipo de remuneración. Esto fue así hasta que a finales del siglo XVI Toyotomi Hideyoshi comenzara la división de la sociedad en clases estancas, registran-

43. A.R.S.I., Jap. Sin. 22, f. 314 y ss. Averiguación de las causas...

44. A.R.S.I., Jap. Sin. 22, f. 314 y ss. Averiguación de las causas...

45. TOTMAN, Conrad, A History of Japan, Blackwell, Oxford, 2000, p. 202. 
do a la población en censos que distinguían a una clase guerrera (samurái) de una clase campesina. Una clase samurái que ya había sufrido las consecuencias del uso en masa de los arcabuces, convirtiéndose en algo así como una metáfora del conflicto entre lo viejo y lo nuevo en el campo de batalla. Desde que llegaran los arcabuces se estaba sucediendo la evolución de una guerra protagonizada por una elite de héroes militares, maestros de las armas tradicionales, a una guerra masificada, protagonizada por la infantería, de un modo similar a lo ocurrido en Europa en el tránsito del mundo medieval a la era moderna. Cientos de balas eran más efectivos que una sola catana, por mucho que la blandiera un maestro de la espada. Y con todo su dolor, los samuráis más nostálgicos tuvieron que admitir que la catana, el alma del samurái, debía ceder su protagonismo al arcabuz, que no era más que un instrumento fácilmente manejado por la chusma.

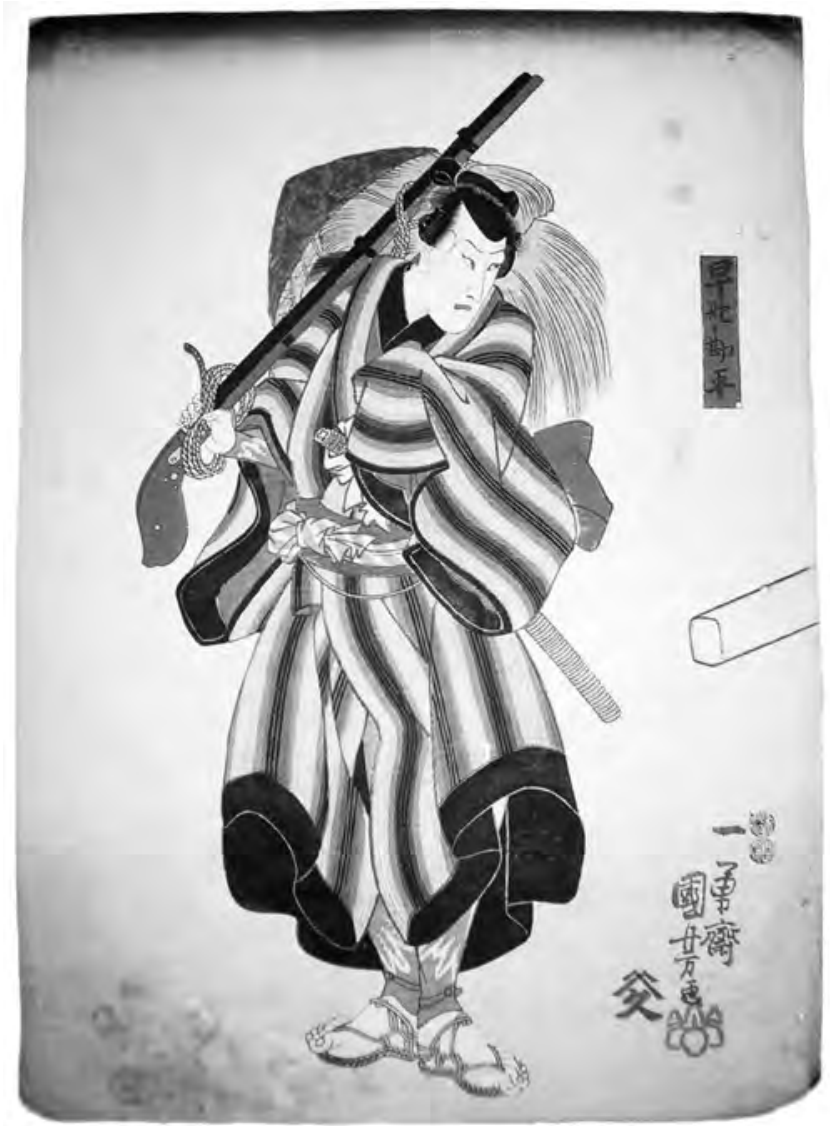

Hombre con mosquete, de Utagawa Kuniyoshi (1797-1861), posible data: 1847. Fuente: http://theloyal47ronin.blogspot.com/2009/08/utagawa-kuniyoshi-1797-1861-manwith.html. Consultado el 25/05/2011. 
Mientras que arcabuces y mosquetes resultaron decisivos en numerosas batallas, la artillería pesada no tuvo tanto protagonismo. Pocas veces fue empleada en batallas campales y las fortalezas niponas estaban diseñadas de tal manera que poco podía hacer un cañón coetáneo contra sus muros de piedra. Su uso estaba más bien enfocado a crear un efecto psicológico, que en cualquier caso era mucho más importante que los daños materiales que pudieran ocasionar: el ruido que provocaban y su poder destructor causaban pánico en el ejército rival.

Algunos historiadores, como Charles Ralph Boxer, se sorprenden de que los japoneses no adoptaran de forma masiva las técnicas europeas, teniendo en cuenta la avidez con que habían asumido las técnicas militares occidentales durante los años que iban desde la Revolución Meiji hasta la Segunda Guerra Mundial (1868-1941) ${ }^{46}$. El autor hace notar que la artillería no volvió a ser empleada después de la batalla de Shimabara, olvidando, al perecer, que a partir de entonces se abriría un periodo conocido como la "paz Tokugawa", un lapso de doscientos años durante el cual un arcabuz serviría para poco más que de adorno en un toko-no-ma de algún señor feudal japonés.

\section{Bibliografía}

ÁLVAREZ TALÁDRIZ, José Luis, "El padre viceprovincial Gaspar Coelho, ¿capitán de armas o pastor de almas?", Sapientia, Eichi Universit 6 (1972), pp. 41-79.

-, (ed.), Documentos franciscanos de la cristiandad de Japón: (1593-1597). Relaciones e informaciones de San Martín de la Ascensión y Fray Marcelo de Ribadeneira, Osaka, 1973.

BERRY, Mary Elizabeth, Hideyoshi, Massachusetts and London, 1989.

BRYANT, Anthony, Sekigahara 1600: The final struggle for power, London, 1995.

BRYANT, Anthony y McBRIDE, Angus, Samurai (1550-1600): weapons, armour, tactics, London, 1988.

BOXER, Charles Ralph, The Christian Century in Japan 1549-1650, Berkeley, 1951.

- Portuguese merchants and missionaries in feudal Japan 1543-1640, London, 1986.

DANVERS, F. Ch. y FOSTER, W., Letters Received by the East India Company, London, 1896-1900. 6 Vols.

ESCALANTE, Bernardino de, Discurso de la navegación que los portugueses hacen a los reinos y provincias del oriente, Sevilla, 1577.

HALL, John Whitney, El imperio japonés, Madrid, 1970.

LAMERS, Jeroen P., Japonius Tyrannus, The Japanese Warlord Oda Nobunaga Reconsidered, Leiden, 2000.

46. BOXER, Charles Ralph, The Christian Century in Japan 1549-1650, Berkeley, 1951, p. 206. 
MASSARELLA, Derek, A World Elsewhere. Europe's Encounter with Japan in the Sixteenth and Seventeenth Centuries, Yale University Press, New Haven \& London, 1990.

MORGA, Antonio de (O.F.M.), Sucesos de las Islas Filipinas. Crónicas y memorias, Madrid, 1997.

MURDOCH, James, A History of Japan, Routledge, 1996.

SADLER, A. L., The maker of modern Japan: the life of Tokugawa leyasu, Rutland, 1989.

SOLA CASTAÑO, Emilio, Relaciones entre España y Japón, tesis doctoral inédita dirigida por d. Vicente Rodríguez Casado, Madrid, 1971.

STORRY, Richard, A History of Modern Japan, London, 1960.

TOTMAN, Conrad, A History of Japan, Oxford, 2000.

TURNBULL, Stephen, Kawanakajima 1553-64. Samurai power struggle, London, 2003.

—, Osaka 1615: The last battle of the samurai, Osprey, New York, 2006.

TURNBULL, Stephen, Samuráis, La Historia de los Grandes Guerreros de Japón, Barcelona, 2006.

VALIGNANO, Alessandro (S.I.), Apología de la Compañía de Jesús de Japón y China (1598), Osaka, 1998.

-, (S.I.), Sumario de las cosas de Japón y Adiciones del Sumario de Japón (1583), Tokyo, 1954.

VV.AA., Técnicas bélicas del mundo oriental (1200-1860). Equipamiento, técnicas y tácticas de combate, Barcelona, 2009.

WHITNEY HALL, J., El imperio japonés, Madrid, 1970.

FROIS, Luis (S.I.), História de Japam, Lisboa, 1984, Vol. IV. 